\title{
Phylogenetic Analysis of Complete $r R N A$ Gene Sequence of Endoreticulatus sp. Shengzhou from the Silkworm, Bombyx mori in Zhejiang of China
}

\author{
${ }^{1,2}$ Haihong Qiu, ${ }^{1}$ Xingmeng Lu, ${ }^{1}$ Mingqian Li, ${ }^{1}$ Xinyi He and ${ }^{1}$ Xiangkang He \\ ${ }^{1}$ College of Animal Sciences, Zhejiang University, 310058 Hangzhou, China \\ ${ }^{2}$ Department of Biological and Chemical Engineering, Shaoyang University, 422000 Shaoyang, China
}

\begin{abstract}
Researchers employed a sample method directly using purified spores suspension instead of genomic DNA as PCR templete for amplifying complete $r R N A$ genes of Endoreticulatus sp. Shengzhou, a novel microsporidian isolate from silkworm Bombyx mori collected in Shengzhou of China and studied its phyletic evolution of the isolate. The complete $r R N A$ gene sequences of the isolate was 4,431 bp long and the arrangement of the $r R N A$ genes was reversed as 5'-LSU-ITS-SSU-IGS-5S-3'. Morphological character and phylogenetic analysis based on the SSU $r R N A$ gene sequence and ITS sequence indicated that Endoreticulatus sp. Sheng zhou is closely related to Endoreticulatus genus.
\end{abstract}

Key words: Microsporidia, Endoreticulatus sp., parasite, phylogeny, Shengzhou, China

\section{INTRODUCTION}

Microsporidia which are unicellular eukaryotes and obligate intracellular parasites have long been recongnized pathogenic agents in sericulture, apiculture and fisheries (Wittner, 1999). Microsporidia were previously divided into primitive eukaryotes however, more and more molecular evidences have demonstrated that these organisms are phylogenetically related to the fungi with remnant mitochondrial organelles (Hirt et al., 1999; Keeling et al., 2000; Thomarat et al., 2004; James et al., 2006; Goldberg et al., 2008; Lee et al., 2008). It is reported that microsporidia consist of approximately 160 genera and 1300 described species (Corradi et al., 2008). Several microsporidian genera such as Nosema bombycis, Pleistophora, Thelohania, Vairimorpha and Endoreticulatus have been found to infect the silkworm Bombyx mori (Lu and Jin, 2000; Bhat et al., 2009). Besides, $N$. bombycis, the genus Endoreticulatus has drawn increased attention because of its widely distribution and interference on inspection of Pebrine (Eric et al., 1998; Wang et al., 2005; Xu et al., 2011). The research on the morphology, spore surface proteins and infectivity had been conducted on Endoreticulatus sp. Shengzhou (Huang et al., 2004a, b). However, no molecular biological work has been carried out on this organism and its taxonomic position had not been completely ascertained. Here, researchers employed a simple method directly using purified spores suspension instead of genomic DNA as PCR templete for amplifying complete $r R N A$ genes of the isolate. By comparing sequences of the Small
Subunit (SSU) rRNA and Internal Transcribed Spacer (ITS) of Endoreticulatus sp. Shengzhou with the corresponding sequences of the other microsporidia, researchers provide molecular biological evidence confirming the taxonomic position of the new isolate.

\section{MATERIALS AND METHODS}

Purification of spores: Endoreticulatus sp. Shengzhou was originally isolated from infected silkworms collected from Shengzhou Sericultural Experimental Station, Zhejiang province, China. Spores were propagated and purified as previously described (Hung et al., 1998; Gatehouse and Malone, 1998; Tsai et al., 2003; Johny et al., 2006). Following quantified with a hemocytometer purified spores were stored in deionized water supplemented with antibiotics (Sigma, $100 \mathrm{mg} \mathrm{mL}^{-1}$ streptomycin, $100 \mathrm{U} \mathrm{mL}^{-1}$ penicillin) at $4^{\circ} \mathrm{C}$ for later use (Zhang et al., 2007).

Morphological observation of the microsporidia isolate: The purified spores of the microsporidia isolate were observed under phase-contrast microscopy (Nikon eclipse $\mathrm{Ti}$ ) and photographed using the digital sight DS-U2 camera system (Nikon).

Ultrathin sections were cut with a diamond knife mounted on the Reichert-Jung ULTRACUT E ultramicrotome stained in methanolic uranyl acetate and then in lead citrate. The stained grids were observed by using the JEM-1230 (JEOL Ltd.) transmission electron microscope operated at $100 \mathrm{kV}$. 
J. Anim.Vet. Adv., 11 (7): 1056-1062, 2012

Table 1: Primers used to sequence the $r R N A$ gene of Endoreticulctus sp. Shengzhou

\begin{tabular}{|c|c|c|c|}
\hline Primers & Sequences & Renaturation temperature $\left({ }^{\circ} \mathrm{C}\right)$ & Amplicon size (bp) \\
\hline $5^{\prime}$ end of LSU rRNA & & & 600 \\
\hline LSUF & 5'-АСТCTCCTCTTTGCCTCAATCAATC-3' & 58.01 & \\
\hline HGR & 5'-CTCCTTGGTCCGTGTTTCA-3' & 57.80 & \\
\hline LSU rRNA & & & 1,757 \\
\hline HGF & 5'-GAAACACGGACCAAGGAGATTAC-3' & 57.80 & \\
\hline ILSUR & 5'-ACCTGTCTCACGACGGTCTAAAC-3' & 61.95 & \\
\hline $3^{\prime}$ end of LSU rRNA and ITS & & & 499 \\
\hline ILSUF & 5'-TGGGTTTAGACCGTCGTGAG-3' & 62.00 & \\
\hline $\mathrm{S} 33 \mathrm{R}$ & 5'-ATAGCGTCTACGTCAGGCAG-3' & 62.00 & \\
\hline SSU rRNA & & & 1,254 \\
\hline $18 \mathrm{f}$ & 5'-CACCAGGTTGATTCTGCC - $3^{\prime}$ & 57.30 & \\
\hline $1537 \mathrm{r}$ & 5'-TTATGATCCTGCTAATGGTTC-3' & 54.11 & \\
\hline IGS and $5 \mathrm{~S}$ rRNA & & & 419 \\
\hline ISSUF & 5'-GAACCATTAGCAGGATCAT-3' & 54.11 & \\
\hline 5SR & 5'-TACAGCACCCAACGTTCCCAAG-3' & 61.94 & \\
\hline
\end{tabular}

Table 2: SSU rRNA sequences of microsporidia used for produce the phylogenetic tree

Microsporidia name Host name

Endoreticulatus sp. Shengzhou Bombyx mori

Endoreticulatus bombycis $\quad$ Bombyx mori

Endoreticulatus sp. Zhenjiang Bombyx mori

Endoreticulatus sp. Taiwan Ocinara lida

Endoreticulatus sp. Bulgaria

Endoreticulatus schubergi

Endoreticulatus sp. Austria

Pleistophora sp. (ATCC 50040)

Pleistophora sp. (Sd-Nu-IW8201)

Vittaforma corneum

Cystosporogenes legeri

Cystosporogenes operophterae

Vittaforma corneae

Nosema plutellae

Nosemacerance

Nosema spodopterce

Nosema bombycis

Encephalitozoon cuniculi

Lymantria dispor

Lymantria dispor

Thaume topoe a processionea

Agrotis exclamationis

Spodopter depravata

Homo sapiens

Lobesia botrana

Operophtera brumata

Nosema corneum

Plutella xyllostella

Apis mellifera

Spodotera litura

Bombyx mori

Oryctolagus cuniculus

Accession No
JN688870
AY009115
FJ772431
AY502944
AY502945
L39109
EU260046
U10342
D85500
L39112
AY233131
AJ302320
U11046
AY960987
DQ486027
AY747307
AY259631
L39107

instead of genomic DNA were used as PCR template in $50 \mu \mathrm{L}$ reaction. Two controls without DNA and with DNA from silkworm were carried out in parallel in the same Veriti 96 well Thermal Cycler (Applied Biosystems, Foster city, CA, USA), respectively. Initial denaturation temperature parameters were $94^{\circ} \mathrm{C}$ for $8 \mathrm{~min}$, other parameters were selected according to standard PCR condition. PCR products were electrophoresed through $1.0 \%$ agarose gel and visualised by ethidium bromide staining.

The products consistent with expected size were purified using DNA Extraction and Purification kit and cloned into pMD20-T Vector (Takara) and the resultant positive clones with the correct size were sequenced with three duplications by Invitrogen Company in Shanghai, China.

Phylogenetic analysis of the microsporidia isolate: The SSUrRNA sequence of the microsporidia isolate was imported into NCBI (http://www.ncbi.nlm.nih.gov/blast/) and blasted with the Blastn program in nucleotide collection (nr/nt) database to obtain other $r R N A$ gene sequences with higher homology microsporidian (Table 2). All sequences were aligned by using the ClustalX 1.83 program. Both the neighbor-joining 
algorithm (Saitou and Nei, 1987) and the maximum parsimony method (Kolaczkowski and Thornton, 2004) implemented in MEGA 5.0 Software (Tamura et al., 2011) was employed to reconstruct phylogenetic trees and Bootstrap support was evaluated based on 1,000 replicates. The SSUrRNA gene sequence of Encephalitozoon cuniculi was used as outgroup.

\section{RESULTS AND DISCUSSION}

Morphological character of the microsporidia isolate: Light microscopy revealed that the spores of the mocrosporidia isolated were ovate in shap and they had an average size of $2.69 \pm 0.12 \times 1.66 \pm 0.12 \mu \mathrm{m}$ (mean \pm standard error, $\mathrm{n}=50$ ) under phase-contrast microscope (Fig. 2a). The isolated was considerably smaller than Nosema bombycis (Fig. 2b). Electron micrography of a longitudinal section of a mature spore revealed that spore consisted of an endospore and an exospore with a wavy outline. The coiled region of the polar tube comprised 9 turns and the monokaryotic nuclei was encapsulated in sporoplasm which was enclosed by a plasma membrane. At the posterior end of the spore was a membrane-bound vacuole with amorphous content

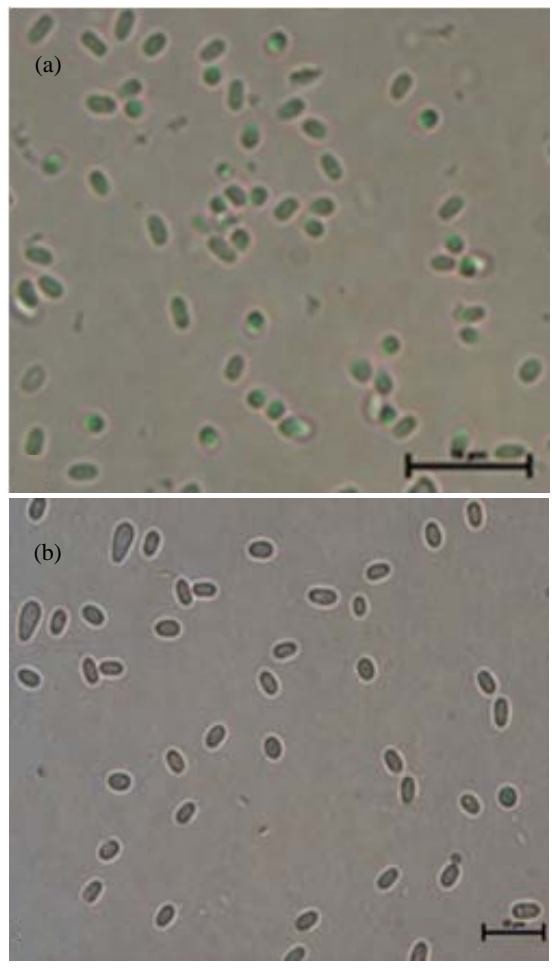

Fig. 2: Light micrographs of; a) Endoreticulatus sp. Sheng zhou and b) Nosema bombycis and (x1,000). Scale bar $=10 \mu \mathrm{m}$
(Fig. 3). All the above-mentioned features correspond to the principle characteristics of the genus Endoreticulatus (Brooks et al., 1988).

The amplication of complete $r R N A$ genes of Endoreticulatus sp. Shengzhou: Using purified spores instead of genomic DNA as PCR template, complete $r R N A$ genes of the Endoreticulatus sp. Shengzhou were successfully amplified. The PCR results with various combinations of the primers shown in Table 1 and in Fig. 4 and the resultant amplicons were of the predicted length (Lane 1-10). Conversely, none of the $\mathrm{PCR}$ reactions using DNA from silkworm with either the primer set $18 \mathrm{f} / 1537 \mathrm{r}$ or the other primer sets produced any amplicon (Lane 11) indicating that PCR products are really origined from microsporidian and there was no interference between the two genomes. For extraction of genomic DNA from microsporidia, traditional method is to get enough cytoplasm released from spores which were stimulated with physical and chemical conditions to germinate (Higes et al., 2007) or broken with glass beads (Undeen and Cockburn, 1989; Rao et al., 2007). The procedure is complex and time consuming. Ombrouck et al. (1997) reported that boiling of spores suspension appeared to be most effective for DNA extraction. However, the PCR results show that purified spores suspension of the Endoreticulatus sp. Shengzhou may be directly used as template to amplify $r R N A$ genes and cumbersome extraction of genomic DNA can be

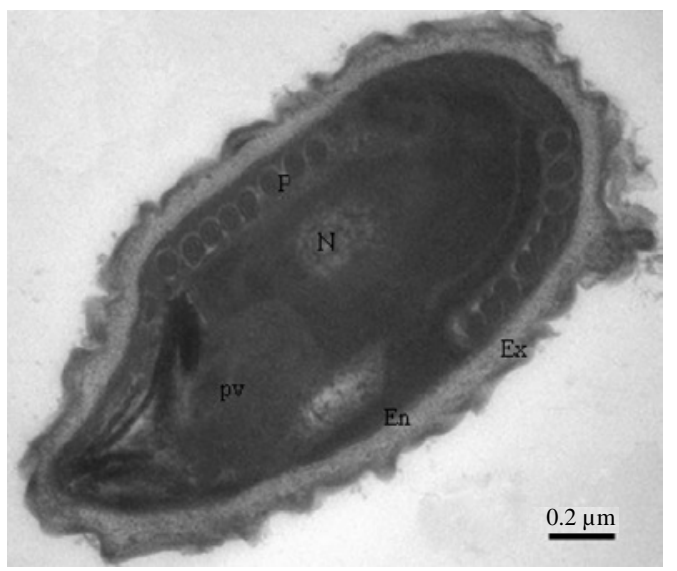

Fig. 3: Transmission electron micrographs of Endoreticulatus sp. Sheng zhou. The extremity of longitudinal section of spore was in a tip shape rather than regular ovate showing extrusion of polar tube with a attempt to penetrate spore wall. En: Endospore; Ex: Exospores; N: Monokaryotic; P: Polar tube and pv: posterior vacuole 


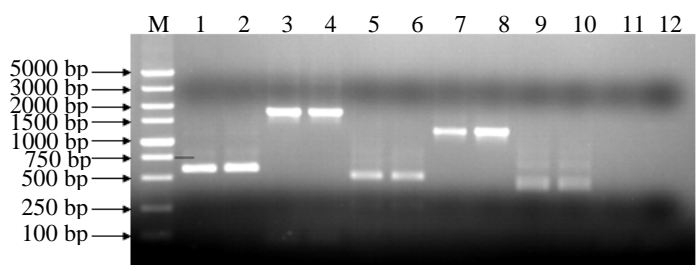

Fig. 4: About 1.0\% agarose gel electrophoresis of PCR products. Lane 1 and 2: 5 ' region of LSUrRNA (primer set LSUF/HGR; $600 \mathrm{bp}$ amplicon), lane 3 and 4: main part of LSUrRNA (primer set HGF/ILSUR; 1757 bp amplicon), lane 5 and 6: $3^{\prime}$ end of LSUrRNA-ITS-5' end of SSUrRNA ( primer set ILSUF/S33R; 509 bp amplicon), lane 7 and 8: SSUrRNA (primer set 18f $/ 1537 \mathrm{r} ; 1254 \mathrm{bp}$ amplicon), lane 9 and 10: 3 ' end of SSUrRNA-IGS5S (primer set, ISSUF/5SR; 319 bp amplicon), lane 11: masculine control with DNA from silkworm (primer set $18 \mathrm{f} / 1537 \mathrm{r}$ ), lane 12: negative control without DNA (primer set 18f/1537r), lane1, 3, 5 and 7: the PCR templete comes from purified spore suspension, lane 2, 4, 6 and 8: the PCR templete comes from genomic DNA and M: 5,00 bp DNA ladder (Takara)

avoided. So, researchers suggest that purified spores suspension can directly be used as PCR template to amplify some genes of microsporidia.

The sequence and organization of rRNA from the isolated: The complete DNA sequence of Endoreticulatus sp. Shengzhou $r R N A$ gene obtained in the present study contains of 4,431 bp. The Large Subunit gene (LSU $r R N A$ ) contains 2,461 bp with $43.48 \% \mathrm{G}+\mathrm{C}$; Internal Transcribed Spacer (ITS) contains 177 bp with $22.09 \% \mathrm{G}+\mathrm{C}$; the Small Subunit gene (SSU rRNA) with the accession number JN688870 contains 1,254 bp with $50.96 \%$ G + C; Intergenic Spacer (IGS) contains 283 bp with $27.21 \% \mathrm{G}+\mathrm{C}$ and 5SrRNA region contains 115 bp with 45.22\% G+C (Fig. 1).

The typical $r R N A$ gene order of microsporidia is SSU-ITS-LSU and conforms with the general arrangement of the rRNA operon where the SSU precedes the LSU from the 5'-3' direction. Different from the typical order, the Endoreticulatus sp. Shengzhou has a reversed arrangement as 5'-LSU-ITS-SSU-IGS-5S-3' (Fig. 1). The reversed organization also has been found in several species of the microsporidian genus Nosema and regarded as a specific characteristic for identifying Nosema species (Huang et al., 2004a, b; Tsai et al., 2005; Ku et al., 2007; Zhu et al., 2011). Moreover, the similar

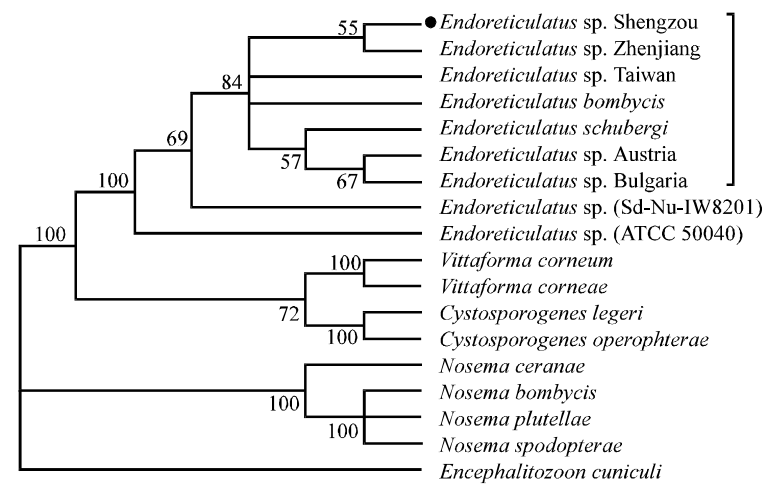

Fig. 5: Phylogenetic analysis of Endoreticulatus sp. Shengzhou based on Smaller Subunit (SSU) $r R N A$ gene. Phylogenetic tree constructed by the Neighbor Joining algorithm (NJ) Method based on the SSU $r R N A$ gene sequences of Endoreticulatus sp. Shengzhou and 17 microsporidian species. The tree is rooted using Encephalitozoon cuniculi as an outgroup. The numbers of the nodes indicate the level of bootstrap support (\%) based on 1,000 resampled date sets

rearrangement of the $r R N A$ genes has occurred in both Glugoides intestinalis (Refardt and Mouton, 2007) and Endoreticulatus sp. Zhenjiang ( $\mathrm{Xu}$ et al., 2011). We provide another evidence that this rearrangement happened independently of the rearrangement in the Nosema species and it is not sufficient to identify Nosema species by the the arrangement of rRNA subunits.

Molecular phylogenetic analysis: Sequences and arrangement of rRNA are extensively used as important molecular parameters for identifying microsporidia at present (Vossbrinck and Debrunner-Vossbrinck, 2005; Hibbett et al., 2007). Here, researchers aligned the SSUrRNA gene sequence of Endoreticulatus sp. Shengzhou with those of other known microsporidia that infect lepidopteran as well as nonlepidopteran hosts. Phylogenetic tree was constructed with the neighborjoining analysis and the maximum parsimony analysis based on the SSUrRNA (Fig. 5). In the analysis based on SSUrRNA, Endoreticulatus sp. Shengzhou and Endoreticulatus sp. Zhenjiang (GenBank accession no. FJ772431.1) fall into a same clade as other Endoreticulatus species including Endoreticulatus sp. CHW-2004 Taiwan (GenBank Accession No. AY502944.1), Endoreticulatus bombycis (GenBank Accession No. AY009115.1), Endoreticulatus schubergi (GenBank Accession No. L39109.1), Endoreticulatus sp. CHW2008 Austria (GenBank Accession No. EU260046.1) and 


\begin{tabular}{|c|c|}
\hline E. Shengzhou & -------CCTTCACGTGGTA \\
\hline N.heliothidis & AAAAATACCTTCACGTGGTA \\
\hline Nb.strain & --- CCTTCACGTGGT \\
\hline E. Zhenjiang & 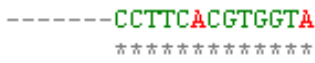 \\
\hline E. Shengzhou & AมGTATTÄTTÄTATTT-TTT \\
\hline N.heliothidis & ӒВGTAДATTATATT-TTT \\
\hline $\mathrm{Mb}$. strain & AДGTAАДTTATATT-TTT \\
\hline E. zhenjiang & 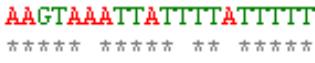 \\
\hline E. Shengzhou & АТАTTTTÄСАТT-СТTТ \\
\hline N.heliothidis & ATATTTTATCATT-СТTT \\
\hline Wb.strain & АTATTTTATCGTTTCTTT \\
\hline E. zhenjiang & 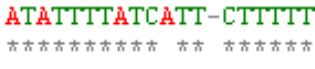 \\
\hline E. Shengzhou & TAMATARGTTGTABG 177 \\
\hline N.heliothidis & 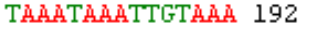 \\
\hline Mb.strain & TAAHTAAGTTGTAAA 185 \\
\hline E. Zhenjiang & 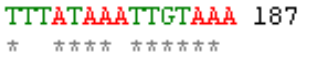 \\
\hline
\end{tabular}

Fig. 6: Alignment of the ITS sequences of Endoreticulatus sp. Shengzhou (E. Shengzhou), Nosema heliothidis, Nosema bombycis strain GD 5 and Endoreticulatus sp. Zhenjiang. E. Shengzhou: Endoreticulatus sp. Shengzhou; $N$. heliothidis; Nosema heliothidis; Nb. strain: Nosema bombycis strain GD 5; E. Zhenjiang: Endoreticulatus sp. Zhenjiang

Endoreticulatus sp. CHW-2004 Bulgaria (GenBank Accession No. AY502945.1). That the seven microsporidia within the same clade suggests the genus Endoreticulatus widely distribute in the nature and have a variety of host. On the basis of the results of analyses, Endoreticulatus sp. Shengzhou was assigned to the genus Endoreticulatus. A molecular biological proof was offered to ascertain the taxonomic position of Endoreticulatus sp. Shengzhou.

Internal Transcribed Spacer (ITS) of $r R N A$ gene is located in the region between LSUrRNA and SSUrRNA. The sequences of ITS are hypervariable in base composition among different species, since ITS has no mature ribosome, suffers less selection pressure and keep a rapid speed of evolution. Thus, ITS is also used for species identification (Garcia-Martinez et al., 1999; James et al., 1996). ITS of Endoreticulatus sp. Shengzhou is different from that of Endoreticulatus sp. Zhenjiang, though the two organisms are located in the same cluster on the phylogenetic tree based on the SSUrRNA. The former contains $177 \mathrm{bp}$ with $22.09 \% \mathrm{G}+\mathrm{C}$ but the latter is composed of 187 bp with $17.11 \% \mathrm{G}+\mathrm{C}$. Between two ITS, there are ten deletions and 24 bp different sites, thirten transition sites and eleven transversion sites and the ratio of transition and transversion was approximately 1.18. The ITS sequences of Endoreticulatus sp. Shengzhou, Endoreticulatus sp. Zhenjiang, Nosema heliothidis
(L28965.1) and Nosema bombycis strain GD 5 (JF443623.1) were analyzed by multi-sequence alignment and these sequences are shown in Fig. 6.

Compared with ITS sequences of other three microsporidia, the ITS sequence of Endoreticulatus sp. Shengzhou also occurres some bases deletions, transitions and transversions. The variation of ITS sequences may be caused by different regions and hosts which result in extensive influence on the development and evolution of microsporidia. So, we presume that SSUrRNA gene sequences combined with ITS sequences can give a reasonable classification for microsporidia once enough ITS sequences are available and that Endoreticulatus sp. Shengzhou is a new species.

\section{CONCLUSION}

This study introduces a simple method for ampilifying some genes of microsporidia without extracting genomic DNA. Spores suspension can be directly used as PCR template to qucikly ampilify gene of microsporidia. Besides morphological character, the study also provides a molecular biological evidence based on SSURRNA gene sequences and ITS sequences in support of the argument that Endoreticulatus sp. Shengzhou isolated from the silkworm Bombyx mori belongs to the genus Endoreticulatus. 


\section{ACKNOWLEDGEMENTS}

This research was supported by the Natural Science Foundation of China (Project No.: 30270898). Researchers are grateful to all laboratory members and the partners for their kind help and criticism. We also thank everyone who generously provided us with access to the software used in this research.

\section{REFERENCES}

Bhat, S.A., I. Bashir and A.S. Kamili, 2009. Microsporidiosis of silkworm, Bombyx mori L. (Lepidoptera-bombycidae): A review. Afr. J. Agric. Res., 4: 1519-1523.

Brooks, W.M., J.J. Becnel and G.G. Kennedy, 1988. Establishment of Endoreticulatus N. G. for Ple istophora fidelis (Hostounsky and Weiser, 1975) (Microsporida: Pleistophoridae) based on the Ultrastructure of a microsporidium in the colorado potato beetle, Leptinotarsa decemlineata (Say) (Coleoptera: Chrysomelidae). J. Eukaryot. Microbiol., 35: 481-488.

Corradi, N., A. Gangaeva and P.J. Keeling, 2008. Comparative profiling of overlapping transcription in the compacted genomes of microsporidia Antonospora locustae and Encephalitozoon cuniculi. Genomics, 91 : 388-393.

Eric, P., B. Corinne, P. Pierre, D. Francis and M. Guy et al., 1998. Microsporidian Encephalitozoon cuniculi, a unicellular eukaryote with an unusual chromosomal dispersion of ribosomal genes and a LSU rRNA reduced to the universal core. Nucleic Acids Res., 26: 3513-3520.

Garcia-Martinez, J., S.G. Acinas, A.I. Anton and F. Rodriguez-Valera, 1999. Use of the $16 \mathrm{~S}-23 \mathrm{~S}$ ribosomal genes spacer region in studies of prokaryotic diversity. J. Microbiol. Meth., 36: 55-64.

Gatehouse, H.S. and L.A. Malone, 1998. The ribosomal RNA gene region of Nosema apis (Microspora): DNA sequence for small and large subunit rRNA genes and evidence of a large tandem repeat unit size. J. Invertebr. Pathol., 71: 97-105.

Goldberg, A.V., S. Molik, A.D. Tsaousis, K. Neumann and G. Kuhnke et al., 2008. Localization and functionality of microsporidian iron-sulphur cluster assembly proteins. Nature, 452: 624-628.

Hibbett, D.S., M. Binder, J.F. Bischoff, M. Blackwell and P.F. Cannon et al., 2007. A higher-level phylogenetic classification of the Fungi. Mycol. Res., 111: 509-547.
Higes, M., P. Garcia-Palencia, R. Martin-Hernandez and A. Meana, 2007. Experimental infection of Apis mellifera honeybees with Nosema ceranae (Microsporidia). J. Invertebr. Pathol., 94: 211-217.

Hirt, R.P., J.M. Logsdon, B. Healy, M.W. Dorey, W.F. Doolittle and T.M. Embley, 1999. Microsporidia are related to fungi: Evidence from the largest subunit of RNA polymerase II and other proteins. Proc. Natl. Acad. Sci., 96: 580-585.

Huang, S.K., X.M. Lu, F.W. Wang, W. Jin and S.U. Chen, 2004a. Comparative study on spore surface proteins of two microsporidia and their infectivity to silkworm Bombyx mori. Canye Kexue, 30: 157-163.

Huang, W.F., S.J. Tsai, C.F. Lo, S. Yamane and C.H. Wang, 2004b. The novel organization and complete sequence of the ribosomal RNA gene ofi Nosema bombycis. Fungal Genet. Biol., 41: 473-481.

Hung, H.W., C.F. Lo, C.C. Tseng, S.E. Peng, C.M. Chou and C.H. Kou, 1998. The small subunit ribosomal RNA gene sequence of Pleistophora anguillarum and the use of PCR primers of diagnostic detection of the parasite. J. Eukaryot. Microbiol., 45: 556-560.

James, S.A., M.D. Collins and I.N. Roberts, 1996. Use of an rRNA internal transcribed spacer region to distinguish phylogenetically closely related species of the genera Zygosaccharomyces and Torulaspora. Int. J. Syst. Bacteriol., 46: 189-194.

James, T.Y., Kauff, F., Schoch, C.L., P.B. Matheny and V. Hofstetter et al., 2006. Reconstructing the early evolution of fungi using a six-gene phylogeny. Nature, 443: 818-822.

Johny, S., S. Kanginakudru, M.C. Muralirangan and J. Nagaraju, 2006. Morphological and molecular characterization of a new microsporidian (Protozoa: Microsporidia) isolated from Spodoptera litura (Fabricius) (Lepidoptera: Noctuidae). Parasitology, 132: 308-314.

Keeling, P.J., M.A. Luker and J.D. Palmer, 2000. Evidence from beta-tubulin phylogeny that microsporidia evolved from within the fungi. Mol. Biol. Evol., 17: 23-31.

Kolaczkowski, B. and J.W. Thornton, 2004. Performance of maximum parsimony and likelihood phylogenetics when evolution is heterogeneous. Nature, 431: $980-984$.

$\mathrm{Ku}$, C.T., C.Y. Wang, Y.C. Tsai, C.C. Tzeng and C.H. Wang, 2007. Phylogenetic analysis of two putative Nosema isolates from Cruciferous Lepidopteran pests in Taiwan. J. Invertebr. Pathol., 95: 71-76.

Lee, S.C., N. Corradi, E.J. Byrnes III, S. Torres-Martinez, F.S. Dietrich, P.J. Keeling and J. Heitman, 2008. Microsporidia evolved from ancestral sexual fungi. Curr. Biol., 18: 1675-1679. 
Lu, X.M. and W. Jin, 2000. Taxonomic status of pathogenic microsporidia found in Silkworm, Bombyx mori. Bull. Sci. Technol., 16: 130-137.

Ombrouck, C., L. Ciceron, B. Sylvester, B. Spencer and A. Pierrem et al., 1997. Specific PCR assay for direct detection of intestinal microsporidia Enterocytozoon bieneusi and Encephalitozoon intestinalis in fecal specimens from human immunodeficiency virusinfected patients. J. Clin. Microbiol., 35: 652-655.

Rao, S.N., B.S. Nath, G. Bhuvaneswari and S.R. Urs, 2007. Genetic diversity and phylogenetic relationships among microsporidia infecting the silkworm, Bombyx mori, using random amplification of polymorphic DNA: Morphological and ultrastructural characterization. J. Invertebr. Pathol., 96: 193-204.

Refardt, D. and L. Mouton, 2007. Reverse arrangement of rRNA subunits in the microsporidium Glugoides intestinalis. J. Eukaryot. Microbiol., 54: 83-85.

Saitou, N. and M. Nei, 1987. The neighbor-joining method: A new method for reconstructing phylogenetic trees. Mol. Biol. Evol., 4: 406-425.

Tamura, K., D. Peterson, N. Peterson, G. Stecher, M. Nei and S. Kumar, 2011. MEGA5: Molecular evolutionary genetics analysis using maximum likelihood, evolutionary distance, and maximum parsimony methods. Mol. Biol. Evol., 10.1093/molbev/msr121

Thomarat, F., C.P. Vivares and M. Gouy, 2004. Phylogenetic analysis of the complete genome sequence of Encephalitozoon cuniculi supports the fungal origin of microsporidia and reveals a high frequency of fast-evolving genes. J. Mol. Evol., 59: 780-791.

Tsai, S.J., C.F. Lo, Y. Soichi and C.H. Wang, 2003. The characterization of Microsporidian isolates (Nosematidae: Nosema) from five important lepidopteran pests in Taiwan. J. Invertebr. Pathol., 83: 51-59.
Tsai, S.J., W.F. Huang and C.H. Wang, 2005. Complete sequence and gene organization of the Nosema spodopterae rRNA Gene. J. Eukaryot. Microbiol., 52: 52-54.

Undeen, A.H. and A.F. Cockburn, 1989. The extraction of DNA from microsporidia spores. J. Invertebr. Pathol., 54: 132-133.

Vossbrinck, C.R. and B.A. Debrunner-Vossbrinck, 2005. Molecular phylogeny of the microsporidia: Ecological, ultrastructural and taxonomic considerations. Folia Parasitologica, 52: 131-142.

Wang, C.Y., L.F. Solter, W.H. T'sui, and C.H. Wang, 2005. An Endoreticulatus species from Ocinara lida (Lepidoptera: Bombycidae) in Taiwan. J. Invertebr. Pathol., 89: 123-135.

Wittner, M., 1999. Historic Perspective on the Microsporidia: Expanding Horizons. In: The Microsporidia and Microsporidiosis, Wittner, $\mathrm{M}$. and L.M. Weiss (Eds.). American Society for Microbiology Press, Washington, DC., pp: 1-6.

Xu, X.F., Z.Y. Shen, F. Zhu, H.P. Tao, X.D. Tang and L. $\mathrm{Xu}, 2011$. Phylogenetic characterization of a microsporidium (Endoreticulatus sp. Zhenjiang) isolated from the silkworm, Bombyx mori. Parasitol. Res., 10.1007/s00436-011-2560-8

Zhang, F., X. Lu, V.S. Kumar, H. Zhu, H. Chen, Z. Chen and J. Hong, 2007. Effects of a novel anti-exospore monoclonal antibody on microsporidial Nosema bombycis germination and reproduction in vitro. Parasitology, 134: 1551-1558.

Zhu, F., Z. Shen, X. Guo, X. Xu, H. Tao, X. Tang and L. $\mathrm{Xu}, 2011$. A new isolate of Nosema sp. (Microsporidia, Nosematidae) from Phyllobrotica armata Baly (Coleoptera, Chrysomelidae) from China. J. Invertebr. Pathol., 106: 339-342. 